\title{
Photostabilization of the Herbicide Norflurazon by Using Organoclays
}

\author{
Tomás Undabeytia, ${ }^{, \dagger}$ Shlomo Nir, ${ }^{\dagger}$ Elisha Tel-Or, ${ }^{\ddagger}$ and Baruch Rubin ${ }^{\S}$ \\ Seagram Center for Soil and Water Sciences, Department of Agricultural Botany, and Department of Field \\ Crops, Vegetables and Genetics, Faculty of Agricultural, Food and Environmental Quality Sciences, \\ The Hebrew University of J erusalem, P.O. Box 12, Rehovot 76100, I srael
}

\begin{abstract}
Photostable formulations of the herbi cide norflurazon [4-chl oro-5-(methylamino)-2-( $\alpha, \alpha, \alpha$-trifluorom-tolyl)pyridazin-3-(2H)-one] were achieved by adsorbing it on pillared clay or on montmorillonite preadsorbed with the organic cation thioflavin T (TFT). Diffuse reflectance F ourier transform infrared spectra showed the existence of strong interactions between the aromatic moi eties of preadsorbed TFT and the herbicide, particularly after irradiation. The photostabilization of norflurazon obtained with TFT-clay was mainly due to energy transfer from the herbicide to the organic cation via $\pi-\pi^{*}$ interactions. An additional mechanism is the lower production of radicals from the clay when the clay mineral surface is covered with the organic cation. These radicals are responsible for the enhanced photodegradation observed when norflurazon was irradiated in the presence of untreated montmorillonite.
\end{abstract}

Keywords: Norflurazon; thi oflavin T; montmorillonite; pillared clay; photostabilization

\section{INTRODUCTION}

Photochemical degradation is an important mechanism of dissipation of herbicides in soils. On dry, sunlight-exposed surfaces photolysis may dominate other transformation pathways that are favored under conditions found in the bulk soil (Misra et al., 1997). In the case of soil, direct photolysis is assumed to be operable only on or within $0.1-0.5 \mathrm{~mm}$ of the surface, and thus its potential contribution as a dissipation mechanism could be limited once a precipitation event has flushed the herbicide into the soil. However, the upward movement of the herbicides with capillary rise of the water front to the surface can occur in the field under conditions of net negative water balance (Sheppard et al., 1987; Strek, 1998). Indirect photochemical processes can also be an important route for the degradation of the herbicide because a variety of oxidants are formed on the sunlight-exposed soil surface that can potentially transform herbicides (Herbert and Miller, 1990; Katagi, 1992, 1993).

Norflurazon is a widely used soil-applied herbicide labeled for grass and broadleaf weed control in several crops, such as cotton, soybean, and citrus (Ahrens, 1994; Wilcut et al., 1997). Its primary mode of action involves blocking carotenoid biosynthesis by inhibition of phytoene desaturase. Hubbs and Lavy (1990) reported that photodegradation contributes significantly to its field dissipation.

In general, several approaches have been used to decrease the loss of herbicides by photodegradation, for

* Address correspondence to this author at the Institute of Natural Resources and Agrobiology, Apdo. 1052, 41080 Sevilla, Spain (telephone +34-954624711; fax +34-954624002; e-mail undabeyt@irnase.csic.es).

+ Seagram Center for Soil and Water Sciences.

₹ Department of Agricultural Botany.

$\S$ Department of Field Crops, Vegetables, and Genetics. example, chemical modification of the herbicide molecule to obtain new photostable herbicides and the use of UV-absorbing molecules in commercial formulations (Elliot et al., 1974; Bridges et al., 1992; J ordan and J ohnson, 1998). Margulies et al. (1985, 1993) suggested the use of clay minerals in the design of new photostable formulations of herbicides. This method is based on the sorption of the photolabile bioactive compound on the surface of clays to which a selected organic chromophore has been previously attached. The chromophore can absorb the excess of energy from the photoexcited mol ecule of the herbicide by energy-transfer or chargetransfer mechanisms, which lengthens the lifetime of the herbicide. Some degree of photostabilization was achieved by using the unmodified clay (Margulies et al., 1992; El-Nahhal et al., 1999). The dose rate of this herbicide applied in the field could be increased to compensate for its photodegradation. However, new environmental issues would arise from increasing the amount of herbicide applied because norflurazon has been reported to leach in porous soils with low organic matter content (Reddy et al., 1992).

The aim of the current study is to develop organoclay formulations of the herbicide norflurazon, which would provide effective photoprotection of the herbicide. Thus, the amount of active ingredient applied to the soil would be lowered, and the economic and environmental costs will decrease. We also focus on the use of a polyoxoaluminum pillared clay as a potential photostabilizer.

\section{MATERIALS AND METHODS}

Materials. The clays used were a standard montmorillonite (SWy-1) (van Olphen and Fripiat, 1979) supplied by the Clay Minerals Society and an alumina pillared montmorillonite (ALFULCAT 2C) (J ones et al., 1997; Mishael et al., 1999) supplied by the National Technical University of Athens, Greece. Analytical and technical grade norflurazon, 99.9 and $97.8 \%$ purities, respectively, were kindly supplied by Novartis 


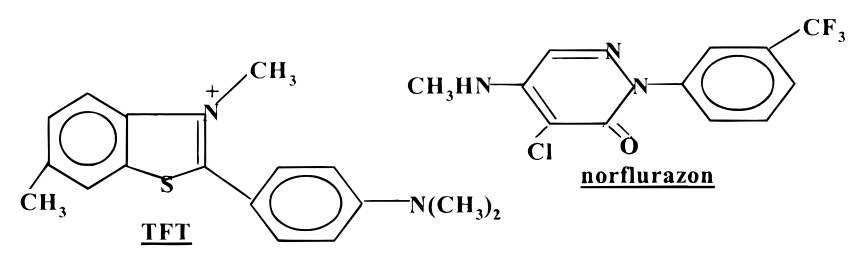

Figure 1. Structural formulas of the herbicide and the organic cation thioflavin $\mathrm{T}$.

A.G. (Basel, Switzerland). Thi oflavin T (TFT), 2,5-dimethylfuran, p-nitroacetophenone, and N,N-dimethylformamide were purchased from Sigma-Aldrich-Fluka (Sigma Chemical Co., St Louis, MO); 2-propanone and hydrogen peroxide were from Frutarom Labor atory Chemicals ( $\mathrm{H}$ aifa, I srael); pyridine was from BDH Laboratory Supplies (Poole, U.K.); and HPLC grade acetonitrile and HPLC grade water were from Merck (Darmstadt, Germany). The structural formulas of norflurazon and TFT are shown in Figure 1.

Preparation of the Organomontmorillonite Complexes. These complexes were prepared by dropwise addition of aliquots of $10^{-2} \mathrm{M}$ TFT to an aqueous suspension of montmorillonite under continuous stirring. The final suspension was $1 \%(w / v)$. After $24 \mathrm{~h}$ of stirring, the suspensions were centrifuged at $20000 \mathrm{~g}$ for $20 \mathrm{~min}$, the supernatant was discarded, and the samples were freeze-dried. The final loads of TFT were 0.2 and $0.5 \mathrm{mmol} / \mathrm{g}$ (denoted TFT 0.2 or 0.5 , respectively).

Preparation of Formulations. Formulations from herbicide dissolved in water (denoted by " $w$ ") were prepared by dissolving technical norflurazon up to the sol ubility limit; the solutions were filtered through a $0.45 \mu \mathrm{m}$ Millipore filter and mixed with pillared clay or organoclay, the final suspension being $0.5 \%(\mathrm{w} / \mathrm{w})$. The suspensions were stirred for $24 \mathrm{~h}$ and thereafter centrifuged. The supernatant was discarded, and the pellets were freeze-dried. The active ingredient (ai) content (w/w) was $0.42 \%$ for montmorillonite-TFT $0.2,0.35 \%$ for montmorillonite-TFT 0.5 , and $0.70 \%$ for pillared clay. Formulations from herbicide dissolved in 2-propanone (denoted by "a") were also prepared for pillared clay and montmorillonite preadsorbed with TFT at 0.2 and $0.5 \mathrm{mmol} / \mathrm{g}$ by dissolving the herbicide in 2-propanone and mixing the solution with the clay, the suspension being 3\% (w/w). The solvent was evaporated using a rotavapor, and the same procedure was repeated five times to enhance the interactions between the herbicide and the clay surface. The final ai content (w/w) for the formulations prepared from 2-propanone was $15 \%$. The rotavapor was used during each cycle for a very long time to ensure that no 2-propanone was remained; IR spectra recorded of the formulations did not show any characteristic absorption bands of 2-propanone.

Irradiation Procedures. Photolysis was carried out within a Rayonet photoreactor (The New England UItraviolet Co.) equipped with 14 RPR 3500 lamps, having a peak output at $350 \mathrm{~nm}$. The power was $24 \mathrm{~W}$ per lamp. The reactor was placed horizontally, and samples were in sealed quartz tubes $(10 \times$ $130 \mathrm{~mm}$ ) containing $8 \mathrm{~mL}$ of norflurazon solutions and suspensions of clay/organoclay formulations of the herbicide, the initial ai content for the irradiation experiments being $65.85 \mu \mathrm{M}$. The tubes were also held in a horizontal position in a merry-go-round arrangement and secured at both ends, rotating to ensure equal exposure of the samples. Photolysis runs were carried out in duplicate for irradiation times from 15 to $120 \mathrm{~min}$. No norflurazon degradation was detected in dark controls.

Photoproducts and remaining norflurazon were extracted from the clay matrix by transferring the solution/suspensions to polycarbonate tubes, adding ethanol $(8 \mathrm{~mL})$, and mixing for 2 min using a vortex mixer (model $\mathrm{K}-550-\mathrm{G}$ ) operating at the highest speed. The tubes were centrifuged and the supernatants analyzed. Preliminary experiments indicated that norflurazon was completely recovered from the formulations. Norflurazon was determined by using a Merck-Hitachi HPLC equipped with a fluorescence detector as described by William and Mueller (1994).
Photolysis experiments were al so carried out under natural light conditions. Quartz tubes with solutions of norflurazon and suspensions of norflurazon in the presence of clay were exposed to full sunlight at an angle of $\sim 30^{\circ}$ from vertical. The remaining norflurazon was determined after exposure times from 30 min to 5 days as described above.

Chloride release from photolysis of norflurazon was followed as a function of the irradiation time. Chloride was determined by using a DX-300 ion chromatograph (Dionex Corp., Sunnyvale, CA), using an AS9 analytical column and guard column together with an anion micromembrane suppressor and carbonate/bicarbonate buffer as eluent.

Assay of Active Oxygen Species. The possible involvement of oxygen species in photolysis was examined. The production of singlet oxygen was followed by the rate of disappearance of aliquots of 2,5-dimethylfuran added to the solutions under study and formation of its photoproduct. After irradiation for an appropriate period, the reaction was quenched by the addition of methanol $(4 \mathrm{~mL})$, and the supernatants were analyzed by HPLC equipped with a diode array detector. The mobile phase was acetonitrile/water (70:30) at $1 \mathrm{~mL} / \mathrm{min}$ flow, and the detection wavelength was $225 \mathrm{~nm}$. The involvement of hydroxyl radicals was examined by using Fenton's reagent. Ferrous sulfate $(0.138 \mathrm{mg}, 0.62 \mathrm{~mL})$ was added to $8 \mathrm{~mL}$ of norflurazon formulations $(65.85 \mu \mathrm{M})$ containing $30 \mu \mathrm{M}$ hydrogen peroxide and shaken for $15 \mathrm{~min}$. The oxidation was repeated twice by readdition of oxidant, followed by addition of ferrous sulfate.

Spectroscopic Measurements. UV-vis spectra were recorded by using a Hewlett-Packard 8452A spectrophotometer. Diffuse reflectance F ourier transform infrared (DRIFT) spectra were obtained with a Nicolet Magna-IR-550. The spectra were recorded at room temperature in the range of $400-4000 \mathrm{~cm}^{-1}$. The emission spectrum of norflurazon was recorded with an SLM OP450 fluorometer.

Bioassays. The herbicidal activity of irradiated and nonirradiated samples was tested in bioassays by using magenta vessels containing $1.63 \mathrm{~g}$ of the aquatic plant Lemna minor in $200 \mathrm{~mL}$ of water. The activity of the formulations was foll owed by measuring their bleaching effect on Lemna plants after 1 week, in comparison to a control that did not receive any application of the herbicide. For this purpose a doseresponse curve was established by using the commercial formulation (Zorial, $80 \% \mathrm{w} / \mathrm{w}$, Novartis). An inhibition percentage of $35 \%$ was obtained for a solution concentration of $0.8 \mathrm{mg} / \mathrm{L}$, which was used as the effective initial concentration for all of the experiments with clay formulations. The water loss by evaporation was replenished every day. Chlorophyll of $\mathrm{L}$. minor plants was extracted with $4 \mathrm{~mL}$ of $\mathrm{N}, \mathrm{N}$-dimethylformamide; the solutions were incubated for $48 \mathrm{~h}$, and the chlorophyll content was measured by visible spectroscopy at 664 and $647 \mathrm{~nm}$ and related to the fresh weight of the plants. The experiment was carried out four times for each formulation. Blanks indicated no release of the organic cation TFT.

\section{RESULTS AND DISCUSSION}

Photolysis of Norflurazon. Irradiation of norflurazon solutions produces deschloronorflurazon as the main photoproduct (Ahrens, 1994). We observed a very good agreement between the amounts of chloride released and degraded norflurazon (data not shown).

Irradiation of Clay Formulations. The half-life time of irradiated norflurazon in its organoclay formulations produced from water is $\sim 4$-fold larger than that from its analytical solutions (Table 1). The photostabilization is less efficient when clay formulations in which norflurazon was added from 2-propanone are irradiated, which could be attributed to the presence of herbicide molecules loosely adsorbed and not interacting with the organic cation. 
Table 1. Photodegradation of Norflurazon and Its Organoclay Formulations: Half-Life Times $\left(t_{1 / 2}\right)$, Kinetic Constants, and Regression Coefficients of Analytical Norflurazon (NFZ), Organoclay Formulations, and the Herbicide in the Presence of Montmorillonite (SWy, 3.125 g L $^{-1}$ Clay Concentration)

\begin{tabular}{lccc}
\hline \multicolumn{1}{c}{ system } & $\mathrm{t}_{1 / 2}(\mathrm{~min})$ & $\mathrm{k} \times 10^{3} \mathrm{a}\left(\mathrm{min}^{-1}\right)$ & $\mathrm{R}^{2}$ \\
\hline NFZ & 54.2 & $12 \mathrm{~b}$ & 0.94 \\
SWy-TFT 0.2-NFZ (w) & 200.9 & $3 \mathrm{c}$ & 0.97 \\
SWy-TFT 0.2-NFZ (a) & 136.4 & $5 \mathrm{~d}$ & 0.92 \\
SWy-TFT 0.5-NFZ (w) & 194.1 & $4 \mathrm{c}$ & 0.92 \\
SWy-TFT 0.5-NFZ (a) & 126.4 & $5 \mathrm{~d}$ & 0.95 \\
PC-NFZ (w) & 292.4 & $2 \mathrm{e}$ & 0.82 \\
PC-NFZ (a) & 134.3 & $5 \mathrm{~d}$ & 0.98 \\
SWy & 37.3 & $19 \mathrm{a}$ & 0.95
\end{tabular}

a Means with the same letter are not significantly different at the $5 \%$ level as determined by Student's multiple-range test. The notations " $(w)$ " and " $(a)$ " indicate formulations prepared in water and 2-propanone, respectively, as described under Materials and Methods. The kinetic parameters were obtained by fitting the experimental data to a first-order kinetic reaction.

Photostabilization of norflurazon in organoclay formulations might be due to energy- or charge-transfer processes from the herbicide to the organic cation. On the other hand, competitive absorption of UV by the organic cation is not expected because of the low absorbance of TFT at $\sim 350 \mathrm{~nm}$ (Margulies et al., 1988a). Table 1 shows a somewhat unexpected result that in the presence of clay suspensions of montmorillonite, the rate of norflurazon photodegradation is enhanced.

The highest degree of photostabilization of norflurazon was obtained with the pillared clay formulation (Table 1). In the case of the herbicide metolachlor (Nennemann et al., 2000), its high adsorption on pillared clay was attributed to the formation of hydrogen bonds between the strong donor sites of the acid-activated pillared clay and the acceptor sites of the herbicide molecule. Spectroscopic evidence by I R of isolated $\mathrm{O}-\mathrm{H}$ groups of the pillared clay interacting with norflurazon was not possible (spectra not shown) due to the background of $\mathrm{H}$-bonded hydroxyls interacting strongly with water molecules. Thus, we are not sure which mechanisms are involved in the photostabilization of norflurazon by pillared clays.

The efficiency of energy-transfer processes depends on the matching of energy levels of donor and acceptor chromophores, on the distance between them, and on their relative orientations (Margulies et al., 1993). The feasibility of energy-transfer processes from norflurazon to TFT is shown in Figure 2, which indicates an overlap between the emission spectrum of norflurazon and the absorption spectrum of the organic cation adsorbed on the clay. Energy transfer would involve $\pi-\pi^{*}$ transitions between triplet states, because the absorption band of the organoclay complex centered at $418 \mathrm{~nm}$ is essentially of $\pi-\pi^{*}$ character $\left(\epsilon=26138 \mathrm{M}^{-1} \mathrm{~cm}^{-1}\right.$, the peak shifts to longer wavelengths when solvent polarity increases). This is in agreement with the suggestion by $\mathrm{Nir}$ et al. (2000) that the adsorption of several hydrophobic herbicides, such as alachlor and norflurazon, on organomontmorillonite is due to $\pi-\pi^{*}$ interactions between the phenyl ring of the herbicide and the aromatic moieties of the organic cation.

Information regarding intermolecular interactions can be obtained by using infrared spectroscopy. In Figure 3 , the spectrum of norflurazon shows absorption bands due to the vibration modes of the pyridazinone ring at 1410 and $1530 \mathrm{~cm}^{-1}$ (Sánchez-Martín and Sánchez-

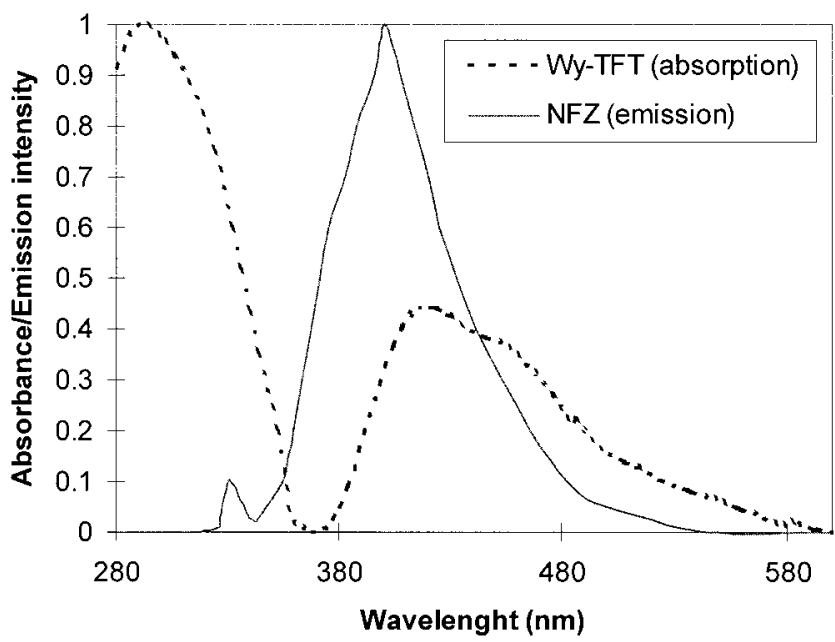

Figure 2. Normalized emission spectrum of norflurazon and absorption spectrum of TFT adsorbed on the clay at a loading of $0.2 \mathrm{mmol} / \mathrm{g}$ of clay.

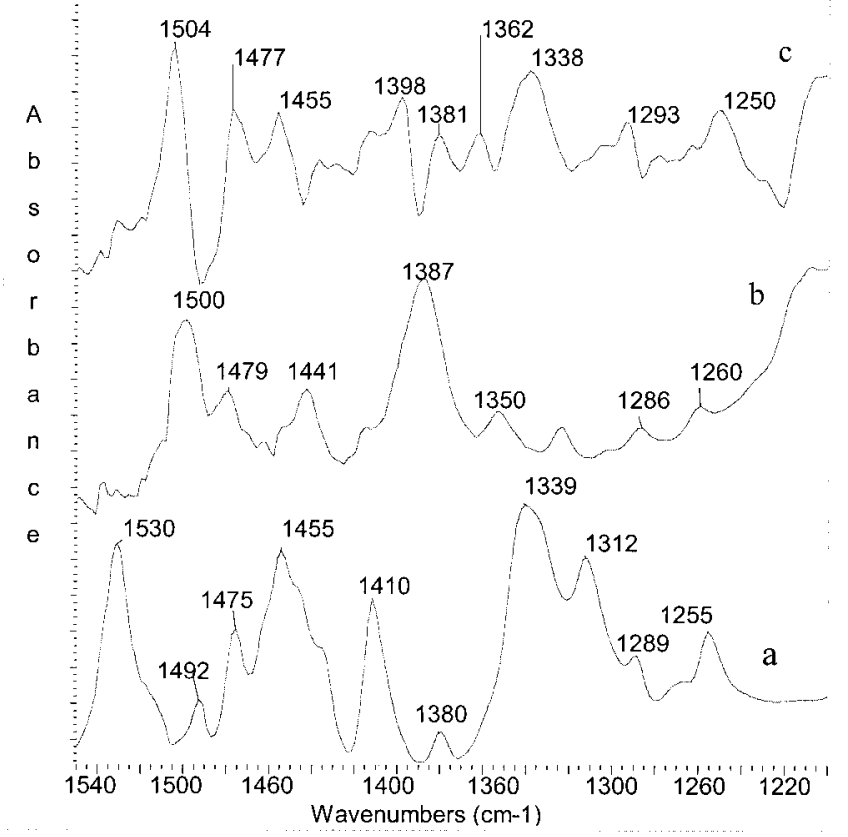

Figure 3. DRIFT spectra of analytical norflurazon (a) and montmorill onite preadsorbed with TFT $(0.2 \mathrm{mmol} / \mathrm{g}$ of clay) (b) and the spectrum of norflurazon adsorbed on the organoclay complex after $2 \mathrm{~h}$ of irradiation, from which its spectrum without irradiation was subtracted (c).

Camazano, 1987), the breathing modes of the phenyl ring at 1475 and $1455 \mathrm{~cm}^{-1}$, the $\mathrm{C}$ aromatic-N stretching frequency at $1339 \mathrm{~cm}^{-1}$, the $\mathrm{C}-\mathrm{N}$ stretching vibrations of the enamine group at $1289 \mathrm{~cm}^{-1}$ (Margulies et al., 1988a), the $\mathrm{C}-\mathrm{F}$ stretching frequency at $1312 \mathrm{~cm}^{-1}$, and the $C$ aliphatic- $N$ stretching at $1255 \mathrm{~cm}^{-1}$. The most important absorption bands for the organoclay are those due to the thiazol ring at 1500 and $1387 \mathrm{~cm}^{-1}$ (Pouchert, 1981), the $\mathrm{C}-\mathrm{H}$ deformation band of methyl attached to $\mathrm{N}$ at $1441 \mathrm{~cm}^{-1}$, the breathing modes of the phenyl ring at $1479 \mathrm{~cm}^{-1}$, and the C aliphatic-N and C aromatic-N stretching frequencies at 1260 and 1350 $\mathrm{cm}^{-1}$, respectively.

Specific absorption bands due to the photoproducts could not be resolved in the norflurazon spectrum after subtraction of the spectrum of the organoclay formulation irradiated from the one corresponding to the nonirradiated organoclay (Figure 3c). Previous infrared 
Table 2. Remaining Herbicidal Activity in Norflurazon Formulations after Irradiation for $\mathbf{2}$ h As Determined by Using L. minor Bioassays

\begin{tabular}{|c|c|c|c|}
\hline formulation & $\begin{array}{l}\text { inhibitiona } \\
\text { (\% of control) }\end{array}$ & formulation & $\begin{array}{l}\text { inhibitiona } \\
\text { (\% of control) }\end{array}$ \\
\hline $\begin{array}{l}\text { commercial } \\
\text { PC (w) }\end{array}$ & $\begin{array}{c}0( \pm 3.6) \\
71.0( \pm 1.6)\end{array}$ & $\begin{array}{l}\text { TFT } 0.2(\mathrm{w}) \\
\text { TFT } 0.5(\mathrm{w}) \\
\text { TFT } 0.5(\mathrm{a})\end{array}$ & $\begin{array}{l}49.8( \pm 2.2) \\
49.2( \pm 1.7) \\
35.6( \pm 2.3)\end{array}$ \\
\hline
\end{tabular}

a The standard error is indicated in parentheses.

results showed that molecular interactions between TFT and norflurazon were occurring without irradiation ( $T$. Undabeytia, S. Nir, and B. Rubin, unpublished data). After $2 \mathrm{~h}$ of irradiation, new changes are observed. The most relevant features are the shifts of the absorption bands of TFT from 1387 to $1398 \mathrm{~cm}^{-1}$ and from 1350 to $1362 \mathrm{~cm}^{-1}$ and the appearance of a negative peak at $1385 \mathrm{~cm}^{-1}$. The possibility that this negative peak might be due to an incorrect normalization factor used in the subtraction is unlikely because the TFT peak at 1500 $\mathrm{cm}^{-1}$ appears. These changes in the spectrum indicate that specific intermolecular interactions between the two adsorbed organic molecules, TFT and norflurazon, occur following irradiation. These changes in the aromatic moieties of TFT are suggested to arise from the donation of $\pi$ electrons from the herbicide, which would produce a shift to higher frequencies of stretching ring vibrations (Nakanishi and Solomon, 1977). These results are consistent with an energy-transfer mechanism.

Weruled out charge-transfer processes that have been reported for flavin and anal ogues (Draper and Crosby, 1983). They are able to undergo photochemical reactions to a semiquinoid form in the presence of an electron donor. No absorption bands due to reduced TFT were detected in the infrared spectra, which can be due to a spontaneous oxidation of the reduced dye with groundstate oxygen. The possibility that this mechanism prevails was tested by using the electron donor EDTA as a quencher for electron-transfer reactions. The rate of norflurazon degradation was not affected by the presence of $600 \mu \mathrm{M}$ EDTA (10:1 EDTA/norflurazon ratio) (results not shown).

The degree of photostabilization of clay formulations of norflurazon was compared with the commercial formulation by using a bioassay (Table 2). After $2 \mathrm{~h}$ of irradiation, some of the clay " $w$ " formulations showed $\sim 50 \%$ herbi cidal activity, in contrast to the commercial formulation, which lost all of its activity. Photostabilization is reduced for the TFT 0.5 "a" formulation, indicating that an increase of the loading of the herbicide on the organoclay will decrease its herbicidal activity. This can be due to either larger amounts of loosely adsorbed molecules on the organoclay that are more susceptible to photodegradation or a larger number of impaired interactions between the herbicide molecules and the organodlay, because energy-transfer processes will be dependent on the geometry and distances between the interacting chromophores. The bioassay results parallel those of Table 1; the lowest rate constant of degradation was obtained for the formulation showing the largest herbicidal activity, PC (w).

Irradiation of Norflurazon in the Presence of Montmorillonite. As stated before, the irradiation of norflurazon solutions in the presence of montmorillonite suspensions enhances its photodegradation. This may be caused by the formation of active oxygen species as a result of the irradiation of oxygen or water associated with the clays (Katagi, 1990). Singlet oxygen is formed on soil surfaces irradiated (Gohre and Miller, 1983). Katagi (1993) observed the generation of hydroxyl radicals by exposure of suspended clays to UV light, which accelerated the photodegradation of the insecticide esfenvalerate.

The involvement of singlet oxygen species was determined by the consumption of 2,5-dimethylfuran and formation of its photoproduct. Singlet oxygen reacts with 2,5-dimethylfuran by a cycloaddition to form an ozonide that decomposes in water to give cis-diacetylethylene, which isomerizes to the more stable trans compound (Gohre and Miller, 1983). The singlet oxygen species is not responsible for the enhanced photodegradation of norflurazon in montmorillonite suspensions, because the amount of norflurazon degraded after irradiation of the herbicide solutions in the presence of $200 \mu \mathrm{M}$ 2,5dimethylfuran was not affected by the presence of the trapping agent (results not shown). At the same time, production of singlet oxygen was confirmed by the consumption of 2,5-dimethylfuran and formation of its photoproduct. Efficient charge-transfer processes can take place between adsorbed molecules and lattice iron of clay minerals (Bergaya and Van Damme, 1983; Rozen and Margulies, 1991).

Photoinduced electron transfer from al uminosilicates to adsorbed molecular oxygen was reported by Che and Tench (1983). On this basis, Katagi (1990) proposed the generation of hydroxyl and hydroperoxyl radicals by reaction of water with $\mathrm{O}_{2}{ }^{--}$formed on clays by irradiation. This author measured the amount of hydrogen peroxide produced by autoxidation of these radicals after irradiation of clay mineral surfaces. The amount determined for montmorillonite after $4 \mathrm{~h}$ of irradiation was $0.9 \mathrm{ppb}$ on a dry weight basis, which should be expected to be considerably larger when aqueous suspensions of this clay mineral are irradiated.

The involvement of these radicals was fol lowed by the addition of Fenton's reagent, which is a well-established system to generate hydroxyl radicals. In addition, oxidation of ferrous ion in the presence of oxygen would generate $\mathrm{O}_{2}{ }^{--}$(Larson et al., 1991). The addition of Fenton's reagent to norflurazon in the presence of the clay resulted in a complete degradation of the herbicide, indicating the involvement of these radicals in the enhanced photodegradation of the herbicide. The opposite trend obtained with organoclay formulations, that is, photostabilization, could be due to the more efficient competition of energy-transfer processes, in addition to lower levels of production of radicals when the clay mineral surface is covered with the organic cation.

Under natural conditions ( $37^{\circ} \mathrm{N}$ latitude, summer), we observed a half-life time of 1.07 days for norflurazon in contrast to its lower half-life in the presence of the clay (0.66 day). These data are in good agreement with those presented in Table 1, which indicate a 1.5-fold enhancement in the rate of herbicide degradation in the presence of the clay. This extremely low half-life time of norflurazon contrasts with that of the herbicide metolachlor, for which Kochany and Maguire (1994) reported half-lives of 22 days under similar conditions.

\section{CONCLUDING REMARKS}

Photostabilization of the herbicide norflurazon was achieved by the devel opment of organod ay formulations. 
A bioassay based on the response of the aquatic plant L. minor showed photostabilizations of norflurazon up to $50 \%$ for formulations prepared from montmorillonite and up to $70 \%$ for that from pillared clay, under irradiation which completely inactivated the commercial formulation. These data demonstrate the potential of pillared clays and organoclays in the development of photostable formulations of norflurazon. Pillared clays have been the subject of research for the past two decades due to the fact that they are cheap materials with physicochemical properties that render them suitable for applications such as filters for detoxifying water or as heterogeneous catalysts for shape selective processes. Formulations based on the organic cation TFT are more expensive. The development of new formulations of other hydrophobic herbicides based on cation, such as TFT, would emphasize its importance and, consequently, its economic viability. The introduction of an additional organic cation such as TFT in herbicide formulations is not expected to cause new environmental issues due to the extremely strong and irreversible binding of TFT on montmorillonite (Margulies et al., 1988b; present work).

Photodegradation of norflurazon was enhanced in the presence of montmorillonite and was attributed to the attack of hydroxyl radicals produced by the clay under irradiation. The results indicate this mechanism as a possible route for degradation of the herbicide in soils and natural waters. However, the importance of this mechanism is li mited because of the presence of organic substances. In intact soils, Katagi (1990) reported that partial coverage of clay minerals with humic substances inhibits efficient electron transfer from clay minerals to adsorbed water and to dissolved oxygen-impeding formation of radicals.

\section{LITERATURE CITED}

Ahrens, W., Ed. Norflurazon. In Herbicide Handbook, 7th ed.; Weed Science Society of America: Champaign, IL, 1994; pp 218-220.

Bergaya, F.; Van Damme, H. Luminescence of $\mathrm{Eu}^{3+}$ and $\mathrm{Tb}^{3+}$ ions adsorbed on hydrated layer-lattice silicate surfaces. J . Chem. Soc., Faraday Trans. 2 1983, 79, 505-518.

Bridges, D. C.; Falb, L. N.; Smith, A. E. Stability and activity of clethodim as influenced by $\mathrm{pH}$, UV light and adjuvant. In Adjuvant for Agrichemicals; Foy, C. L., Ed.; CRC Press: Boca Raton, FL, 1992; pp 215-223.

Che, M.; Tench, A. J. Characterization and reactivity of molecular oxygen species on oxide surfaces. In Advances in Catalysis; Frakenberg, W. G., Komarewsky, V. I., Rideal, E. K., Eds.; Academic Press: New York, 1983; Vol. 32, p 1.

Draper, W. M.; Crosby, D. G. Photochemical generation of superoxide radical anion in water. J. Agric. Food Chem. 1983, 31, 734-737.

Elliot, M.; Farnham, A. W.; J anes, N. F.; Needham, P. H.; Pullman, D. A. Synthetic insecticide with a new order of activity. Nature 1974, 248, 710-711.

El-Nahhal, Y.; Nir, S.; Margulies, L.; Rubin, B. Reduction of photodegradation and vol atilization of herbicides in organoclay formulations. Appl. Clay Sci. 1999, 14, 105-119.

Gohre, K.; Miller, G. C. Singlet oxygen generation on soil surfaces. J . Agric. Food Chem. 1983, 31, 1104-1108.

Herbert, V. R.; Miller, G. C. Depth dependence of direct and indirect photolysis on soil surfaces. J. Agric. Food Chem. 1990, 38, 913-918.

Hubbs, C. W.; Lavy, T. Dissipation of norflurazon and other persistent herbicides in soil. Weed Sci. 1990, 38, 81-88.
J ones, W.; Poncelet, G.; Ruiz-Hitzky, E.; Galvan, J . C.; Pomonis, P.; Van Damme, H.; Bergaya, F.; Papayannakos, N.; Gangas, N. The synthesis, characterisation and application of pillared layered solids (PILCS) produced in large quantities; Synthesis Report of Brite-Euram Contract BRE-CT0629 of the European Community, 1997.

J ordan, D. L.; J ohnson, P. D. I nfluence of adjuvants on efficacy of 2,4-DB, cadre, and strongarm. Proc. South Weed Sci. Soc. 1998, 51, 60-61.

Katagi, T. Photoinduced oxidation of the organophosphorus fungicide tolclofos-methyl on clay minerals. J . Agric. Food Chem. 1990, 38, 1595-1600.

Katagi, T. Photodegradation of 3-phenoxybenzoic acid in water and on solid surfaces. J . Agric. Food Chem. 1992, 40, 12691274.

Katagi, T. Photodegradation of esfenvalerate in clay suspensions. J . Agric. Food Chem. 1993, 41, 2178-2183.

Kochani, J .; Maguire, J . Sunlight photo-degradation of metoIachlor in water. J. Agric. F ood Chem. 1994, 42, 406-412.

Larson, R. A.; Schlauch, M. B.; Marley, K. A. Ferric ion promoted photo- decomposition of triazines. J . Agric. F ood Chem. 1991, 39, 2057-2062.

Margulies, L.; Rozen, H.; Cohen, E. Energy transfer at the surface of clays and protection of pesticides from photodegradation. Nature 1985, 315, 658-659.

Margulies, L.; Rozen, H.; Cohen, E. Photostabilization of a nitromethylene heterocycle insecticide on the surface of montmorillonite. Clays Clay Miner. 1988a, 36, 159-164.

Margulies, L.; Rozen, H.; Nir, S. Model for competitive adsorption of organic cations on clays. Clays Clay Miner. 1988b, 36, 270-276.

Margulies, L.; Stern, T.; Rubin, B.; Ruzo, L. Photo-stabilization of trifluralin adsorbed on a clay matrix. J . Agric. Food Chem. 1992, 40, 152-155.

Margulies, L.; Rozen, H.; Stern, T.; Rytwo, G.; Rubin, B.; Ruzo, L.; Nir, S.; Cohen, E. Photostabilization of pesticides by clays and chromophores. Arch. Insect Biochem. Physiol . 1993, 22, 467-486.

Mishael, Y. G.; Rytwo, G.; Nir, S.; Crespin, M.; AnnabiBergaya, F.; Van Damme, H. Interactions of monovalent organic cations with pillared clays. J . Colloid I nterface Sci. 1999, 209, 123-128.

Misra, B.; Graebing, P. W.; Chib, J. S. Photodegradation of chloramben on a soil surface: a laboratory-controlled surface. J . Agric. Food Chem. 1997, 45, 1464-1467.

Nakanishi, K.; Solomon, P. Infrared Absorption Spectroscopy; Holden Day: San Francisco, CA, 1977; 287 pp.

Nennemann, A.; Mishael, Y.; Nir, S.; Rubin, B.; Polubesova, T.; Bergaya, F.; van Damme, H.; Lagaly, G. Clay-based formulations of metolachlor with reduced leaching. Appl. Clay Sci. 2000, in press.

Nir, S.; Undabeytia, T.; Yaron-Marcovich, D.; El-Nahhal, Y.; Polubesova, T.; Serban, C.; Rytwo, G.; Lagaly, G.; Rubin, B. Optimization of adsorption of hydrophobic herbicides on montmorillonite preadsorbed by monovalent organic cations: interaction between phenyl rings. Environ. Sci. Technol. 2000, 34, 1269-1274.

Pouchert, C. J. The Aldrich Library of Infrared Spectra; Aldrich Chemical Co.: Milwaukee, WI, 1981; 1873 pp.

Reddy, K.; Singh, M.; Alva, A. K. Sorption and desorption of diuron and norflurazon in Florida citrus soils. Water, Air Soil Pollut. 1992, 64, 487-494.

Rozen, H.; Margulies, L. Photostabilization of tetrahydro-2(nitromethylene)-2H-1,3-thiazine adsorbed on clays. J . Agric. Food Chem. 1991, 39, 1320-1325.

Sánchez-Martín, M. J .; Sánchez-Camazano, M. Adsorption of chloridazone by montmorillonite. Chemosphere 1987, 16, 937-944.

Sheppard, M. I.; Thibault, D. H.; Mitchell, J. H. Element leaching and capillary rise in sandy soil cores. J . Environ. Qual. 1987, 16, 273-284.

Strek, H. J . F ate of chlorsulfuron in the environment. 2. Field evaluations. Pestic. Sci. 1998, 53, 52-70. 
van Olphen, H.; Fripiat, J.J. Data Handbook for Clay Materials and Other Non-Metallic Minerals; Pergamon: Oxford, U.K., 1979; 301 pp.

Wilcut, J. W.; J ordan, D. L.; Vencill, W. K.; Richburg, J . Weed management in cotton (Gossypium hirsutum) with soilapplied and post-directed herbicides. Weed Technol. 1997, $11,221-226$.

William, W. T.; Mueller, T. C. Liquid chromatographic determination of norflurazon and its initial metabolite in soil. J . AOAC Int. 1994, 77, 752-755.
Received for review November 8, 1999. Accepted J uly 15, 2000. This research was supported by Grant G-0405095 from GIF, the German-Israeli Foundation for Scientific Research and Development. T.U. acknowledges postdoctoral fellowships from the Spanish Government (Ref. PF 9633975424) and the European Community (Program TMR, Contract FAIR-BM970892)

J F 9912405 